not entirely absent, as in my case. I can confirm this observation so far that on the previous day I used a 4 per cent. solution in operating on the larynx of a delicate woman under my care at St. Bartholomew's Hospital without producing any marked ansesthesia. Yet the application was made twice, and an interval of at least five minutes was allowed between the applications and between the second application and the operation. It is not improbable that a solution of less strength than 20 per cent. will suffice in operations in the interior of the nose, and this will easily be determined during the next few weeks or even days. Indeed, the sooner it is determined the better, for the mariate of cocaine is at present extremely expensive, costing about one shilling a grain. When the 20 per cent. solution is employed, and the nose or larynx is brushed over twice thoroughly, it will be found that from two to four grains of the cocaine have been used. I am informed that the cost will probably increase during the next few months if the drug is as largely employed as it bids fair to be, for the supply is very limited, and there is not even a good prospect of obtaining a sufficient supply of the leaves from which the alkaloid is manufactured.

Nov. 24th (two days after the operation).-Yesterday I suffered from a slight attack of migraine, not so severe as I have often experienced, and not to be compared with that which followed the first cauterisation. To-day it has completely passed off, for it only lasted a few hours. How much of the difference is to be attributed to the use of the cocaine I am not able to say, but I believe a part of it at least. I mention it to make the case as complete as possible, and to show that there is certainly no reason to apprehend that the after-effect of the alkaloid will exaggerate the suffering of the patient. I remain, Sir, yours truly,

Queen Anne-street, W., Nov. 24th, 1884. HeNRY T. BUTLIN.

P.S -Dr. Semon has just looked through this letter, and thinks I ought to have offered some explanation of the reasons which induced him to perform and me to submit to the cauterisation of the turbinated bones for migraine; but I think it will be better to defer that and the discussion of Hack's theory to a later date, when we have more material within our reach. The object of the present communication is to direct attention to another use of cocaine.

\section{FLUKES IN MAN.}

To the Editor of THE LANCET.

SIR,-Having received from Dr. Manson a copy of Dr. Wallace Taylor's paper entitled "Distomata Hominis," I request permission to offer a few criticisms in no unfriendly spirit. Dr. Taylor says that "the whole subject of distomata infesting man has probably been worked up better in Japan than elsewhere." Nevertheless his memoir, which from the clinical standpoint does him much credit, omits all reference to the labours of Lewis, McConnell, Sonsino, Thomas, and others. My papers on Distoma crassum, Bilharzia, \&c., naturally share the same fate.

Dr. Taylor gives a description of Distoma Ringeri, but, following Prof. Baelz, he calls the parasite D. pulmonale. My description of the original fluke sent by Dr. Manson was published in the Quekett Journal in 1880 , two years Klinische Wochenschrift, which he quotes (1883). Baelz, it seems, had mistaken the eggs of this fluke for gregarines. ${ }^{1}$ But apart altogether from the question of priority, the title (D. pulmonale) is badly chosen, because the lung flakes of mammals are so very like one another. The $D$. compactum found by me in the lungs of the Indian ichneumon is apparently a mere variety of, if it be not identical with, $D$. Ringeri of man, and as much may be said of Dr. Kerbert's D. Westermanni infesting the lungs of the tiger. ${ }^{2}$ In all three corresponding forms the uterine organs have precisely the same character and disposition. Certainly Baelz's and Kerbert's figures leave little to be desired.

The second parasite described by Dr. Taylor is still more unfortunately named. He calls it D. hepaticum. Here, again, he follows Baelz, who had previously called it D. hepatis perniciosum. It seems incredible that anyone writing on flukes should be unfamiliar with the natural history and characters of the common D. (Fasciola) hepa-

1 See The LANCET, 1880, vol. ii., pp. 548 . ticum so beautifully worked out by Professor Thomas and already known to have been detected some twenty tines in the human subject; yet Dr. Taylor naively remark that " whether D. hepaticum hominis is of a different specis from the Fasciola hepatica (Linn.), well known in Europe as the cause of the sheep "rot,' I am unable to decids." Dr. Taylor's parasite (D. hepaticum homini ) is utterly unlike the common liver fluke. If it be a good species, it will be less confusing to call Baelz's fluke (D. Baelzl). My inpression is that it is only a contracted or broad example of the species which I have called D. sinense. Dr. Taylor, how. ever, says of his D. hepaticum that, "omiting minor differences, the general description given of the viscera of the D. pulmonale will answer for this." This statement surprises me, for his own, or rather Professor Baelz's, really good figures show that (as regards the position and extent of the vitellaria and other reproductive organs) no two fluke species of the same genus could well be more divergent in the arrangement of their essential organs.

The next species described by Dr. Taylor is Prof. Baelz's so-called Distoma hepatis innocuum. This fancied new parasite is (as Manson himself points out in a pencilled side-note) nothing more than the now well-known D. sinense, of which I have specimens sent by the original discoverer, Prof. McConnell. Unaware of my prior description, Leuckart named the same parasite D. spatulatum. I have part of a liver well infested by this fluke, which is doubtless "per. niciosum" in its effects. Baelz's zoological nomenclature is therefore altogether inadmissible.

Dr. Taylor's memoir closes with figures of two other fluke parasites. Here again he is equally unfortunate in his determinations. The large fluke " infesting the stomach of cattle," which he calls a distoma, is the well-known Ampbistoma conicum, whilst the smaller fluke, taken from the liver of a cat, is probably Creplin's Distoma conus. The size, to be sure, is rather larger than Dujardin states it to be in his description.

The errors which exist in regard to the synonymy of parasitic species are already sufficiently burdensome, and it was in the hope of aiding identification that I published a "Manual of Reference" to all the known human parasites, bringing the literature up to date (1882). Honest and good workers, who are not at the same time systematists, can have little idea of the great trouble and confusion which the introduction of new names for old or familiarly known para. sites creates in medicine. Solely in the hope of checking errors of fluke-nomenclature in relation to important diseases I have made these few remarks, which I trust will be accepted in the spirit in which they are offered.

I am, Sir, your obedient servant,

Portsdown-road, W., Nov. 22nd. T. SPENCER CoBbold,

\section{"CHARCOT'S JOINT DISEASE."}

\section{To the Editor of THE LANCET.}

Sir, - The interest excited by the discussion at the Clinical Society on "Charcot's Disease" induces me to state that you published in THE LANCET of Jan, $28 \mathrm{th}, 1871$, in a report by me of cases under the care of Dr. Charcot at La Salpetière, Paris, the first notice of this disease in England. This report included a very short résumé of the clinical facts, and by what, in considering the diagnosis, rheumatism was excluded. In $1876 \mathrm{I}$ begged of Dr. Charcot that he would kindly give some specimens of bones illus. trating the disease in question. He informed me that the specimens he had shortly before had at his disposal were sent to the museum of St. Thomas's Hospital. May I here have the pleasure to acknowledge that Dr. Charcot did not send me empty-handed away, but gave me sections of the epinal cord in another form of disease-namely, progressive muscular atrophy, which I exhibited at the Pathological Society May, 1877, as having a relationship with the joint affection.

$I$ append an extract from your journal of the date above named. I am, Sir, your obedient servant

Stratford-place, W., Nov. 1884

T. W. NUNN.

"Dr. Charcot pointed out some cases of joint affection which he believed showed that consecutive to lesion of the nervous system arose mischief in the joints. In the Archives de Physiologie, No. 1, 1868, he has published papers: "Sur quelques Arthropathies qui paraissent dépendre d'une Lésion du Cerveau ou de la Moëlle Epinière." The purpose 
of these papers is to describe certain phenomena which are occasionally to be observed during the progress of disease of the nervous centres; and he divides into two groups the joint affections which respectively occur during the progress of locomotor ataxy, and in hemiplegia dependent on disease of one of the cerebral hemispheres."1

\section{ENGLISH DEGREES FOR ENGLISH STUDENTS.}

\section{To the Editor of THR LANCET,}

SIR,-Not only practitioners and students, but all patriotic Englishmen, must agree with the remarks in your leading article of November 1st on the continuous exodus of English medical students from their native schools. This is a matter with which pecuniary considerations have absolutely nothing to do, as at the present day the necessary expenses of medical education vary little on either side of the Tweed, and the fee for the double degree of M.D., M.S., in the North is about the same as that for the usual double qualification in London. I brought this subject forward at the meeting of the Royal College of Surgeons in March last, and then drew attention to the rajid decadence of the English schools of medicine. There is no doubt whatever as to the cause of this. The real explanation, as I then pointed out, is the fact to which you allude, that "no more learning is needed and no greater effort demanded to obtain a diploma of doctor of medicine in other places than is required in London and most of the English schools to obtain a mere licence to practise." This is, indeed, an under-statement of the facts, for in all that concerns medical knowledge and experience much more is demanded of a candidate for the English licence than of a candidate for a Scotch degree, as may be seen by anyone who will compare the regulations of the examining bodies.

A glance at the Medical Directory will show that about 2000 practitioners suffice for the medical requirements of the whole of Scotland, whilst there are more than twice that number in active practice in London alone, and six times the number in addition in the English provinces. But at the medical schools in Scotland there are probably twice as many students as at all the medical schools in London; a considerable proportion moreover of those entering at the London schools find out afterwards the mistake they have made, and go off after one, two, or three years to other schools where their labours will be more fitly rewarded. The result is that the English licentiate is every where thrust aside by the Scotch graduate, and elbowed out of office, employment, and profit; every honorary medical appointment is closed to him by the universal rule admitting only graduates, and he is necessarily relegated to a secondary rank, and is thus and thus only prevented from rising to such a professional position as he might otherwise attain, and to which his qualifications and abilities would give him an indisputable right. 'There is an easy and natural remedy for this state of things without calling upon the London or any of the other universities to lower its standard, and without adding to the excessive number of licensing bodies already existing. At the meeting to which I bave referred I proposed that the two Royal Colleges of Physicians and Surgeons should be amalgamated into one great Royal College of Medicine, to be endowed with the power of granting the degrees of M.D. and M.S. ${ }^{2}$ (see the report in your issue of March 29/h). There is no need to call the United College a University, nor would there be any advantage in doing so. There is nothing either novel or incongruous in a college granting degrees; various instances might be cited from both ancient and modern times, but it will suffice to mention the University of Edinburgh, which was only spoken of as a college for more than a century after its foundation, and which, as Sir Alexander Grant says, "never did and never could become a university in the mediæval sense of the term." Oxford, and Trinity College, Dublin, are now the only universities requiring the B.A. to be taken previously to the M.D., so that as far as medicine is concerned the College of Physicians is practically on exactly the same footing as any of the other universities-it prescribes a curriculum, conducts

"To the title "Roy LANCET, Jan. 28th, 1871, p. 117.
"Roy College of Medicine," the words "and of Physicians and Surgeons of England" could be added as a secondary title if thought desirable, to satisfy the scruples of some who might
regret to part with these time-honoured designations. an examination in, aud grants a diploma for, medicine, which is a licence to practire The moment a university medical degree is dissociated from an Arts degree, and allowed to become a licence to practise, it ceases as such to be any thing more, and the whole of $i t s$ value as a higher title will depend on the character and standard of the particular curricuium and examinations of which it is the end and aim. It cannot surely be difficult for a committee of both Colleges to prepare a scheme of complete union which shall be satisfactory to the English profession. The mere conjunction of the Colleges for examination purposes will not retain students at the London Schools nor make the London qualification more attractive; and if the fees remain exactly as in the separated Colleges, there can be no conceivable advantage ro the English student in a mere corjoint board at all. Although the question of expense enters very little into this question of the driving away of students from the London schools, yet so large fees being charged for primary examinations must rather deter than attract students, and one sees no reason why either College should now charge ten guiness for exactly the same examination that each before charged five guiveas for; it would have been $f_{\star r}$ better to contin ue to charge five guineas for each primary examination and twenty-five guineas for the double pass examination; but a little more liberality in this matter of fees would disarm much opposition to the scheme, and would probably result rather in a gain than a loss in a pecuniary sense.

The present is a great opportunity. On the boldness or hesitation of those who influence the affairs of our two Royal Colleges depends the continuance of the success of our English Schools of Medicine-depends probably the future existence of the Colleges themselves.

I am, Sir, yours obediently,

Dorset-square, N.W., Nor. 10th, 1884. WILLIAME HICKMAN.

\section{"OVER-PRESSURE IN SCHOOLS." To the Editor of THE LANCET.}

SIR,--In The LANCET of Nov, 15th there is a leader or the above subject. Your remarks are well timed and essentially to the point, and I believe that there are few members of our profession who will be found to disagree with their general tenour. The subject is one of vital importance to the future well-being of the nation, and it is a subject, moreover, in the settlement of which the medical profession is peculiarly concerned, for it is impossible, in $\mathbf{m y}$ opinion, for anyone who has made the nature of disease a study and its treatment a practice, to remain in ignorance of the fact that the present system of education is being maintained at a ruinous, and to the general public, almost inexplicable expense. The expense is not a monetary one, but consists in the wasted energies and premature deaths of children, who, in other and more reasonable circumstances, might have lived long and useful lives. To the members of our profession whose daily work brings constantly under observation the relations which the various parts of the human frame bear to one another during life the difficulties which at present roughen the educational road are easily apparent; but it is otherwise with the general, and, as a rule, unthinking mass of the population. The average parent desires that his childre $n$ shall be educated as speedily, as cheaply, and as thoroughly as possible; and he naturally regards with favour a system of education which endeavours to make up for lack of time by an increased amount of material, and it is with feelings of pride that such a parent will tell armiring friends that his boy of ten is almost fit to leave school, and has his head stored with a wonderful amount of learning. The boy often begins to fag and to fall into a state of ill.health which is misunderstood by both parent and schoolnaster, and the educational mill is allowed to grind into dust all the fair promises of early boyhood, ar d upon the very threshold of life this prodigy of youthful learning falls. His brain, over-driven and exhausted, is like a jaded horse, dull and irresponsive at a time when its best efforts are required, and his body, neglected and forgotten, fails with sad and ominous frequency in the performance of its duties; and, in a word, a wasted life is the result, the inevitable result, of a premature and excessive demand upon the higher functions of the human frame. This is, perhaps, a somewhat gloomy picture, but if we consider for a moment the delicate and easily disturbed organiem over which the relentless educational Juggernaut is driven, the reason for 